\title{
Surgical intervention for myocardial bridges: To do or not do to? That is the question
}

\author{
Paul J. Chai, MD
}

\author{
From the Division of Cardiac, Thoracic, and Vascular Surgery, Department of Surgery, Columbia University Med- \\ ical Center, New York, NY. \\ Disclosures: Author has nothing to disclose with regard to commercial support. \\ Received for publication Feb 6, 2018; accepted for publication Feb 10, 2018; available ahead of print March 15, \\ 2018. \\ Address for reprints: Paul J. Chai, MD, Morgan Stanley Children's Hospital of NYP, 3959 Broadway, CHN 275, \\ New York, NY 10032 (E-mail: Pjc2164@cumc.columbia.edu). \\ J Thorac Cardiovasc Surg 2018;156:1617 \\ $0022-5223 / \$ 36.00$ \\ Copyright (c) 2018 by The American Association for Thoracic Surgery \\ https://doi.org/10.1016/j.jtcvs.2018.02.025
}

Myocardial bridge, a congenital abnormality in which a portion of the epicardial coronary artery takes an intramuscular course, can be a controversial topic. Most coronary blood flow occurs in diastole, and so the impact of a myocardial bridge, at least theoretically, should be minimal. Nevertheless, systolic compression of the coronary artery has been associated with angina, ${ }^{1}$ ventricular dysfunction, ${ }^{2}$ and even sudden cardiac death, ${ }^{3}$ and systolic compression of the coronary artery has been demonstrated to impact diastolic flow in the coronary artery. ${ }^{4}$ In this issue of The Journal of Thoracic and Cardiovascular Surgery, Madea and colleagues $^{5}$ from Stanford present their experience with the surgical treatment of myocardial bridges in the pediatric population.

Descriptions of 14 pediatric patients treated for myocardial bridge with unroofing of the left anterior descending coronary artery are presented in the article. All patients had symptoms, and patients with other associated lesions (anomalous aortic origin of the coronary artery) were excluded. There were no deaths or major complications, and all patients with symptoms reported improvement. Madea and colleagues ${ }^{5}$ also demonstrated how their surgical technique has evolved to a more minimally invasive approach.

Some of the limitations of the study include a small patient population and a relatively short follow-up. In addition, the Seattle Angina Questionnaire, which was used to quantify the effectiveness of the procedure, has only been validated among older (60-70 years old) men in the US Department of Veterans Affairs system, and so its accuracy for use in a pediatric population is unclear.

Madea and colleagues ${ }^{5}$ demonstrate that surgical unroofing can be performed safely with minimal morbidity. In truth, this finding is not unexpected and perhaps even assumed. The obvious question, however, is not can the

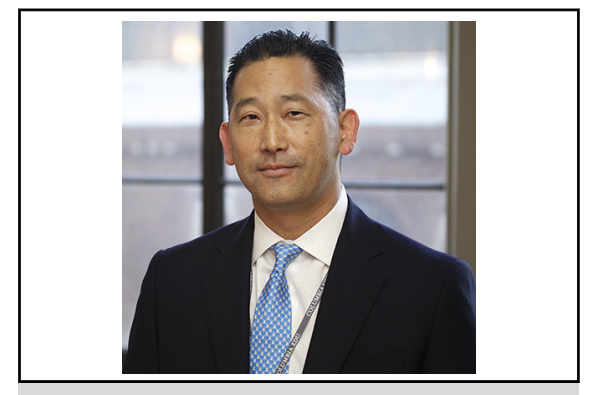

Paul J. Chai, MD

Central Message

Surgical treatment for myocardial bridges can be a controversial topic. Ultimately, the decision to intervene should be an individualized decision.

See Article page 1618.

procedure be performed safely, but rather to which patients should surgery be offered? Unfortunately, this question is beyond the scope of the article to answer. Some draw parallels to the anomalous aortic origin of the coronary artery population; however, there are some important distinctions - risk of sudden death from a myocardial bridge is deemed to be low, and most patients with an isolated symptomatic myocardial bridge are not activity restricted. As a result, it becomes less clear who should be offered surgery for symptoms of chest pain.

Ultimately, when to perform surgical unroofing for a myocardial bridge remains an individualized question. Before that question can be more effectively answered, further studies are needed.

\section{References}

1. Rossi L, Dander B, Nidasio GP, Arbustini E, Paris B, Vassanelli C, et al. Myocardial bridges and ischemic heart disease. Eur Heart J. 1980;1:239-45.

2. Marchionni N, Chechi T, Falai M, Margheri M, Fumagalli S. Myocardial stunning associated with a myocardial bridge. Int J Cardiol. 2002;82:65-7.

3. Cutler D, Wallace JM. Myocardial bridging in a young patient with sudden death Clin Cardiol. 1997;20:581-3.

4. Schwarz ER, Klues HG, vom Dahl J, Klein I, Krebs W, Hanrath P. Functional characteristics of myocardial bridging: a combined angiographic and intracoronary Doppler flow study. Eur Heart J. 1997;18:434-42.

5. Maeda K, Schnittger I, Murphy DJ, Tremmel JA, Boyd JH, Peng L, et al. Surgical unroofing of hemodynamically significant myocardial bridges in a pediatric population. J Thorac Cardiovasc Surg. 2018;156:1618-26. 